\title{
HUBUNGAN PROFIL PETERNAK DENGAN PENDAPATAN USAHA TERNAK KERBAU LUMPUR DI KECAMATAN LINTONG NIHUTA KABUPATEN HUMBANG HASUNDUTAN
}

\author{
(Relationship of Farmers Profile and Farmers Income of Buffalo in The District \\ Lintong Nihuta Kabupaten Humbang Hasundutan)
}

\author{
Natalia Lumbantoruan', Ma'ruf Tafsin², Armyn Hakim Daulay² \\ 1. Mahasiswa Program Studi Peternakan Fakultas Pertanian Universitas Sumatera Utara \\ 2. Staf Pengajar Program Studi Peternakan Fakultas Pertanian Universitas Sumatera Utara
}

\begin{abstract}
The research was conducted in Lintong Nihuta,Humbang Hasundutan District, North Sumatra Province, started from July until August 2012. The purpose of this study was to analyze the relationship of the farmers profile with farmer income of buffalo in Lintong Nihuta Humbang Hasundutan. The method used survey, with respondents that a family unit who maintains buffaloes. The sampling method used is a Proportional Stratified Random Sampling in three villages namely Sitolu Bahal village (16), Nagasaribu Village 1 (20), Village Sigumpar (19), the sample of this research were 55 farmers. The results showed that the scale of business, farmers age, length of education had a positive effect on raising the income of farmers, while experience, number of dependents family and the degree of generation had no effect on farmers income. The conclusion is the scale business, farmer age, length of education is a major factor in increasing the income of farmers buffalo in Lintong Nihuta Subdistrict, Humbang Hasundutan distrct.
\end{abstract}

Keywords: Farmer Profile, farmers income, swamp buffalo, Humbang Hasundutan.

\section{ABSTRAK}

Penelitian ini dilaksanakan di Kecamatan Lintong Nihuta, Kabupaten Humbang Hasundutan, Propinsi Sumatera Utara yang dimulai tanggal Juli sampai Agustus 2012. Tujuan penelitian ini adalah untuk menganalisis pengaruh profil peternak terhadap pendapatan dalam ternak kerbau di kecamatan Lintong Nihuta Kabupaten Humbang Hasundutan. Metode penelitian yang digunakan adalah metode survey dengan unit responden keluarga yang memelihara ternak kerbau. Metode penarikan sampel yang digunakan adalah Proportional Stratified Random Sampling yaitu dengan cara memilih 3 desa yaitu Desa Sitolu Bahal (16), Desa Nagasaribu 1 (20), Desa Sigumpar (19), sampel dari penelitian ini berjumlah 55 keluarga peternak kerbau. Hasil penelitian menunjukkan bahwa skala usaha, umur peternak, lama pendidikan berpengaruh positif terhadap pendapatan peternak. Sedangkan pengalaman beternak, jumlah tanggungan keluarga dan tingkat generasi tidak berpengaruh terhadap pendapatan peternak kerbau. Kesimpulannya adalah skala usaha, umur peternak, lama pendidikan merupakan faktor utama meningkatkan pendapatan peternak kerbau di Kecamatan Lintong Nihuta Kabupaten Humbang Hasundutan.

Kata Kunci : Profil peternak, pendapatan peternak, kerbau lumpur.

\section{PENDAHULUAN}

Tingginya permintaan akan daging terutama asal ternak ruminansia besar tidak dapat dipenuhi secara keseluruhan. Hal ini disebabkan oleh produktivitas ternak rendah, ketersediaan pakan hijauan yang tidak berkualitas dan kontinyu karena sangat dipengaruhi oleh musim.Disamping itu disebabkan oleh pengembangan ternak hanya mengandalkan 
berskala rumah tangga dan di pelihara secara tradisional. Suryana (2000), mengatakan bahwa ketidak mampuan produksi peternakan dalam negeri untuk memenuhi kebutuhan domestik dipengaruhi oleh beberapa keterbatasan antara lain; penguasaan teknologi, baik di bidang produksi maupun di bidang penanganan pasca panen, kemampuan permodalan peternakan, kualitas sumberdaya dapat diandalkan dalam menghasilkan daging dan tenaga kerja bahkan susu, serta memiliki daya adaptasi yang baik terhadap musim kering. Secara umum pemeliharaan kerbau di Indonesia belum ditujukan untuk ternak potong, karena fungsi utamanya untuk mengolah lahan pertanian, sebagai sumber pupuk dan tabungan.

Ternak kerbau merupakan salah satu sumber daya penghasil bahan makanan berupa daging yang memiliki nilai ekonomis tinggi dan penting di dalam kehidupan masyarakat. Sekor atau kelompok ternak kerbau dapat menghasilkan suatu bahan makanan berupa daging, disamping hasil ikutan lainnya seperti pupuk kandang, kulit, tulang dan lain sebagainya. Daging sangat besar manfaatnya bagi pemenuhan gizi berupa protein hewani.

Faktor-faktor yang menyebabkan rendahnya populasi ternak kerbau disebabkan oleh keterbatasan bibit unggul, pemotongan ternak betina produktif, mutu pakan ternak rendah, tidak dilakukan perkawinan silang dan kurangnya pengetahuan peternak dalam menangani produksi dan reproduksi ternak tersebut. Dalam kaitan inilah dirasa perlu untuk mengetengahkan kedudukan kerbau di masyarakat meliputi pemeliharaan, kegunaan dan peluang dalam peningkatan kesejahteraan masyarakat peternak.

Wilayah di Provinsi Sumatera Utara memiliki luas lahan yang mencukupi, ketersediaan hijauan berlimpah, serta pemanfaatan limbah perkebunan yang sangat mendukung dan salah satu daerah penyebaran populasi ternak kerbau yang berpotensi. Perkembangan ternak kerbau pada tahun 2011 di Kabupaten Humbang Hasundutan mencapai 12378 ekor dan di Kecamatan Lintong Nihuta mencapai 2035 ekor (BPS Peternakan Humbang Hasundutan, 2011). Data BPS (2011) menunjukkan bahwa Kecamatan Lintong Nihuta memiliki jumlah peternak yang banyak, sehingga peneliti melakukan survey penelitian di Kecamatan Lintong Nihuta untuk mengetahui faktor sosial ekonomi (skala usaha, umur peternak, tingkat pendidikan, pengalaman beternak, jumlah tanggungan keluarga ,dan tingkat generasi peternak) dan pengeluaran, pemasukan dan pendapatan peternak dalam satu tahun.

Kerbau rawa yang banyak dipelihara masyarakat memang bukan kerbau tipe perah tetapi di beberapa daerah para peternak kerbau melakukan pemerahan. Produksi susu dari setiap ternak kerbau yang diperah berkisar antara 1,50-2,50 liter/ekor/hari dengan lama pemerahan sekitar 7 bulan. 
Sehubungan dengan hal diatas penulis mencoba untuk meneliti seberapa besar pengaruh faktor-faktor sosial ekonomi yang mempengaruhi pendapatan peternak kerbaudi Kecamatan Lintong Nihuta Kabupaten Humbang Hasundutan.

\section{METODE PENELITIAN}

\section{Lokasi dan Waktu Penelitian}

Penelitian ini dilaksanakan di Kecamatan Lintong Nihuta Kabupaten Humbang Hasundutan pada bulan Juli sampai Agustus 2012.

\section{Metode Penetuan Responden Penelitian}

Responden terdiri dari para peternak kerbau di Kecamatan Lintong Nihuta, Kabupaten Humbang Hasundutan. Metode penelitian yang digunakan adalah metode survey dengan unit analisis keluarga yang memelihara ternak kerbau.

Tabel 1. Populasi peternak kerbau di daerah penelitian

\begin{tabular}{lcllr}
\hline & $\begin{array}{c}\text { Desa Naga } \\
\text { Saribu 1 }\end{array}$ & Desa Sitolu Bahal & Desa Sigumpar & Total \\
\hline Populasi & 101 peternak & 66 peternak & 100 peternak & 267 peternak \\
Sampel & 20 peternak & 16 peternak & 19 peternak & 55 peternak \\
\hline
\end{tabular}

Masing-masing jumlah responden akan dilihat dari data populasi peternak, apabila jumlah populasi kecil akan dilakukan sensus sehingga jumlah responden lebih $230 \%$ dari seluruh peternak dari setiap desa Wirartha (2006), menyatakan bahwa untuk penelitian yang akan menggunakan data statistik ukuran paling kecil $30 \%$ sudah dapat mewakili populasi.

\section{Pengumpulan Data}

Data yang dikumpulkan dalam penelitian ini terdiri dari data Primer maupun sekunder. Data Primer diperoleh dari monitoring terhadap kegiatan usaha ternak kerbau melalui wawancara dan pengisian kuesioner. Data sekunder diperoleh dari berbagai instansi yang terkait seperti Badan Pusat Statistik Humbang Hasundutan, Kantor Kecamatan Lintong Nihuta.

\section{Metode Analisis data}

Data yang diperoleh dari hasil wawancara responden di lapangan yang diolah dan ditabulasikan, kemudian data dianalisis dengan menggunakan metode analisis pendapatan dan diolah dengan menggunakan model pendekatan ekonometri dan dijelaskan secara 
deskriptif. Menurut Pryanto (2000), untuk menghitung analisis pendapatan dari kegiatan beternak kerbau dapat dihitung sebagai berikut :

$$
\mathrm{II}=\mathrm{TR}-\mathrm{TC}
$$

Keterangan :

II = Total pendapatan atau keuntungan yang diperoleh peternak kerbau (Rupiah/tahun)

$\mathrm{TR}=$ Total revenue atau penerimaan (Rupiah/tahun).

$\mathrm{TC}=$ Total cost atau pengeluaran yang dikeluarkan oleh peternak kerbau (Rupiah/tahun).

Berdasarkan hasil yang diperoleh, maka untuk memperoleh faktor-faktor yang mempengaruhi pendapatan dapat dilihat dengan menggunakan metode pendekatan teknik Ekonometri dengan analisis Regresi Linear Berganda (Alat bantu software seperti SPSS 17) dengan model pendugaan yang digunakan adalah :

$$
\ddot{Y}=a+b_{1} X_{1}+b_{2} X_{2}+b_{3} X_{3}+b_{4} X_{4}+b_{5} X_{5}+b_{6} X_{6}+\mu
$$

\begin{tabular}{|c|c|}
\hline$\ddot{Y}$ & $=$ Pendapatan peternak (rupiah) \\
\hline $\mathrm{a}$ & $=$ Koefisien intercept (konstanta) \\
\hline$b_{1}, b_{2, . .}$ & $=$ Koefisien regresi \\
\hline $\mathrm{X}_{1}$ & $=$ Skala usaha (jumlah peternak) \\
\hline $\mathrm{X}_{2}$ & $=$ Umur peternak (tahun) \\
\hline $\mathrm{X}_{3}$ & $=$ Lamapendidikan (tahun) \\
\hline $\mathrm{X}_{4}$ & $=$ Pengalaman beternak (tahun) \\
\hline $\mathrm{X}_{5}$ & $=$ Jumlah tanggungan keluarga (jiwa) \\
\hline $\mathrm{X}_{6}$ & $=$ Tingkat generasi peternak (generasi) \\
\hline$\mu$ & $=$ Variabel lain yang tidak diteliti \\
\hline
\end{tabular}

Keterangan :

Variabel-variabel pada hipotesis diuji serempak dan parsial untuk mengetahui apakah variabel tersebut memiliki dominan atau tidak. Jika variabel tersebut berpengaruh secara serempak maka digunakan dengan uji F yakni :

$$
F=\frac{r^{2} / k}{\left(1-r^{2}\right) /(n-k-1)}
$$

Keterangan

$$
\begin{array}{ll}
\mathrm{r}^{2} & =\text { Koefisien determinasi } \\
\mathrm{n} & =\text { Jumlah responden } \\
\mathrm{k} & =\text { Derajat bebas pembilang } \\
\mathrm{n}-\mathrm{k}-1 & =\text { Derajat bebas penyebut }
\end{array}
$$


Kriteria uji :

$\mathrm{F}$ hit $\leq \mathrm{F}$ tabel

$\mathrm{H}_{0}$ diterima ( $\mathrm{H} 1$ ditolak)

$\mathrm{F}$ hit $>\mathrm{F}$ tabel

$\mathrm{H}_{0}$ ditolak ( $\mathrm{H} 1$ diterima)

Menurut Sudjana (2002), jika variabel berpengaruh secara parsial, maka dapat diuji:

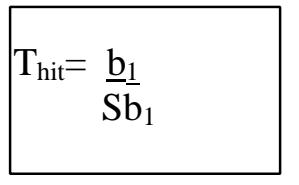

$$
S^{2} y_{123}=\frac{\sum(-y)^{2}}{n-k-1}
$$

$$
\mathrm{S}^{2} \mathrm{~b}_{1}=\sqrt{\frac{s^{2} y_{123}}{\sum X i^{2}\left(1-R 1^{2}\right)}}
$$

Keterangan :

$\begin{array}{ll}\mathrm{b} & =\text { Parameter }(\mathrm{I}=1,2,3,4) \\ \mathrm{n}-\mathrm{k}-1 & =\text { Derajat bebas } \\ \mathrm{S}^{2} \mathrm{~b}_{1} & =\text { Standard eror parameter } \mathrm{b} \\ \mathrm{S}^{2} \mathrm{y}_{1234} & =\text { Standard eror estimates } \\ \mathrm{X}_{\mathrm{i}} & =\text { Variabel bebas }(\mathrm{i}=1,2,3,4)\end{array}$

Kriteria uji :

t-hit $\leq \mathrm{t}$-tabel

$\mathrm{H}_{0}$ diterima ( $\mathrm{H} 1$ ditolak)

t-hit $>$ t-tabel

$\mathrm{H}_{0}$ ditolak (H1 diterima)

\section{Parameter Penelitian}

\section{Karakteristik Responden}

1. Skala usaha adalah jumlah ternak kerbau yang dipelihara (ekor)

2. Umur Peternak yaitu umur peternak yang memelihara ternak kerbau yang diukur berdasarkan usia kerja produktif yaitu 16-60 tahun.

3. Lama Pendidikan yaitu pendidikan formal (SD, SMP, SMA) atau informal

4. Pengalaman peternak lamanya responden/peternak menjalankan usaha ternak kerbau.

5. Jumlah tanggungan keluarga yaitu jumlah tanggungan yang di tanggung peternak dalam satu keluarga (jiwa).

6. Tingkat generasi peternak yaitu generasi keberapa peternak tersebut saat memelihara ternak (Soekartawi, 1995).

2. Analisis Pengeluaran dan biaya Penerimaan

Keterangan

$$
\mathrm{R}=\frac{\mathrm{Q}}{\mathrm{T}} \times 100 \% \quad \mathrm{~S}=\frac{\mathrm{R}}{\mathrm{N}} \times 100 \%
$$

$\mathrm{Q} \quad=$ biaya pengeluaran / biaya penerimaan

$\mathrm{T} \quad=$ jumlah peternak

$\mathrm{R} \quad$ = rataan peternak 
$\mathrm{N} \quad=$ jumlah peternak

3. Analisis pendapatan Bersih

Total Pendapatan $=$ Total pemasukan - Total pengeluaran $($ Siregar, 2012) .

\section{HASIL DAN PEMBAHASAN}

\section{Lokasi Penelitian}

Lokasi penelitian kecamatan Lintong Nihuta terletak di sebelah Timur yang berdekatan dengan Kabupaten Tapanuli Utara, Kabupaten Humbang Hasundutan terletak di ketinggian 330-2075 m di atas permukaan laut, yang kaya dengan hijauan.Pemanfaatan lahan secara optimal dapat dilakukan dengan penanaman berbagai hijauan makanan ternak, baik pada lahan perkebunan maupun pada areal yang tidak terpakai.

\section{Sistem Pemeliharaan Pada Usaha Ternak Kerbau Di Daerah Penelitian}

Sistem pemeliharaan ternak dan manajemen yang baik adalah salah satu kunci dari keberhasilan suatu usaha ternak kerbau. Umumnya pemeliharaan ternak kerbau di kecamatan Lintong Nihuta sebagian besar bersifat ekstensif pada siang hari ternak di gembalakan dan pada malam hari ternak dikandangkan.

Adapun kegiatan-kegiatan yang dilakukan peternak kerbau yang terdapat di daerah penelitian adalah sebagai berikut:

\section{Pemberian Pakan dan Minum}

Ternak akan tumbuh sehat dan berkembang biak dengan pemberian pakan yang teratur, dan bergizi serta melakukan manajemen yang baik. Pakan merupakan unsur yang vital dalam usaha peternakan. Pemberian pakan ternak kerbau di Kecamatan Lintong Nihuta dengan cara digembalakan, pada pagi hari jam 10.00 WIB ternak digembalakan dan sore hari jam 18.00 Wib ternak dikandangkan.

Air minum ternak juga mempunyai fungsi yang vital untuk proses pertumbuhan dan perkembangan tubuh ternak. Pemberian air minun ternak kerbau di lakukan pada siang hari ternak minum di padang penggembalaan, saat ternak berlumpur atau berkubang danpada sore hari di kandang. 


\section{Pembersihan Kandang}

Kandang adalah tempat tinggal ternak sehingga kandang menjadi salah satu faktor penting dalam beternak. Kandang yang bersih dapat menghindarkan ternak dari serangan penyakit.Kandang sangat berpengaruh terhadap kesehatan ternaknya, terutama faktor kelembaban, lumpur dan sarang lalat yang dapat mengganggu kenyamanan serta keleluasaan ternak. Letak kandang harus terpisah dari rumah, namun di daerah penelitian masih ada beberapa responden yang membuat kandangnya menyatu dengan rumahnya.

Lokasi penelitianpembersihan kotoran di dalam kandang dilakukan setiap hari dengan menggunakan cangkul, sekop dan beco sorong, kemudian kotoran dikumpulkan di belakang kandang atau langsung di kumpulkan ke sawah, kotoran ternak dan dimanfaatkan peternak untuk tanaman sendiri, sehingga peternak tidak lagi membeli kompos untuk tanamannya. Pada umumnya peternak tidak melakukan penyemprotan desinfektan pada kandangnya yang bertujuan untuk membunuh kuman-kuman pembawa penyakit.

\section{Karakteristik Responden}

Karakterisitik responden dalam penelitian ini meliputi karakteristik sosial dan ekonomi. Karakteristik sosial peternak yang dianalisis meliputi umur peternak, lama pendidikan, pengalaman beternak, jumlah tanggungan keluarga dan tingkat generasi peternak, sedangkan karakteristik ekonomi responden yang dianalisis meliputi jumlah ternak, total penerimaan dari usaha ternak, total pengeluaran peternak. Karakterisitik responden selengkapnya disajikan pada Tabel 2.

Skala usaha peternak kerbau didominasi pada jumlah ternak 1 ekor sampai 5 ekor dengan banyaknya peternak 26 orang yaitu $47.27 \%$ (Tabel 2). Berdasarkan data tersebut dapat dikatakan bahwa jumlah kepemilikan ternak kerbau dalam usaha beternak masih sedikit, sementara di daerah penelitian masih cukup luas lahan kosong sebagai tempat penggembalaan ternak kerbau dan untuk penanaman hijaun juga masih banyak yang dapat digunakan. Hal ini sesuai dengan pendapat Soekartawi (1995), yang menyatakan bahwa pendapatan usaha ternak sangat dipengaruhi oleh banyaknya ternak yang dijual oleh peternak itu sendiri sehingga semakin banyak jumlah ternak maka semakin tinggi pendapatan bersih yang diperoleh.

Umur peternak dapat didominasikan pada umur 46 tahun sampai 50 tahun dengan jumlah 28 orang yaitu 50,90\% (Tabel 2). Bila dikaji dari karakteristik umur di atas, sebagian besar peternak dalam kategori usia yang produktif (16-60 tahun), sehingga potensi untuk bekerja dan mengelola usaha ternaknya masih besar. Hal ini sesuai dengan pendapat Chamdi 
(2003), yang menyatakan bahwa semakin muda usia peternak (usia produktif 16-60 tahun), umumnya rasa keingintahuan terhadap sesuatu semakin tinggi dan minat untuk mengadopsi terhadap introduksi teknologi semakin tinggi.

Tabel 2. Karakteristik responden di lokasi penelitian tahun 2012

\begin{tabular}{|c|c|c|}
\hline Karakteristik peternak sampel & Satuan & $\%$ \\
\hline Jumlah ternak/ Skala Usaha (ekor) & Jumlah & \\
\hline a. $1-5$ & 26 & 47,27 \\
\hline b. $6-10$ & 18 & 32,72 \\
\hline c. $11-15$ & 9 & 16,36 \\
\hline d. $16-20$ & 1 & 1,81 \\
\hline e. $21-25$ & 1 & 1,81 \\
\hline Umur peternak (tahun) & Orang & \\
\hline a. $30-35$ & 3 & 5,45 \\
\hline b. $36-40$ & 2 & 3,36 \\
\hline c. $41-45$ & 5 & 9,09 \\
\hline d. $46-50$ & 28 & 50,90 \\
\hline e. $51-55$ & 12 & 21,82 \\
\hline f. $56-60$ & 4 & 7,27 \\
\hline g. $61-65$ & - & - \\
\hline h. $66-70$ & - & - \\
\hline i. $71-75$ & 1 & 1,81 \\
\hline Lama pendidikan (tahun) & Orang & \\
\hline a. $6-10$ & 48 & 87,27 \\
\hline b. $11-15$ & 7 & 12,72 \\
\hline Pengalaman peternak (tahun) & Orang & \\
\hline a. $1-5$ & 16 & 29,09 \\
\hline b. $6-10$ & 26 & 47,27 \\
\hline c. $11-15$ & 9 & 16,36 \\
\hline d. $16-20$ & 1 & 1,81 \\
\hline e. $21-25$ & 3 & 5,45 \\
\hline Jumlah tanggungan keluarga (orang) & Orang & \\
\hline a. $1-5$ & 51 & 92,72 \\
\hline b. $6-10$ & 4 & 7,27 \\
\hline Tingkat generasi peternak (generasi) & Orang & \\
\hline a. $1-5$ & 53 & 96,36 \\
\hline b. $6-10$ & 2 & 3,63 \\
\hline
\end{tabular}

Sumber : Data Primer Penelitian (2014)

Lama pendidikan peternak kerbau didominasikan pada 6 tahun sampai 10 tahun dengan jumlah peternak 48 orang dengan jumlah persen 87,27\% (Tabel 2). Hal ini menunjukkan bahwa lamanya pendidikan responden umumnya tergolong Sekolah Dasar (SD), sehingga 
lama pendidikan responden digolongkan rendah. Pendidikan non formal di daerah penelitian yang khusus mengenai usaha ternak kerbau tidak berjalan dengan baik. Hal ini sesuai dengan pendapat Ahmadi (2003), yang menyatakan bahwa keterbatasan keterampilan/ pendidikan yang dimiliki menyebabkan keterbatasan kemampuan untuk masuk dalam dunia kerja.

Pengalaman beternak didominasikan pada 6 tahun sampai 10 tahun dengan banyaknya peternak 26 orang jumlah persen yaitu 47,27\% (Tabel 2). Hal ini menunjukkan bahwa tingkat pengalaman beternak responden dapat dikatakan cukup, tetapi kurang menguasai dan mengikuti perkembangan teknologi dalam pengelolaan usaha ternak kerbaunya. Hal ini sesuai dengan pendapat Hasan (2000), yang menyatakan bahwa semakin banyak pengalaman yang diperoleh petani maka diharapkan produktivitas petani akan semakin tinggi, sehingga dalam mengusahakannya usahatani akan semakin baik dan sebaiknya jika petani tersebut belum atau kurang berpengalaman akan memperoleh hasil yang kurang memuaskan.

Jumlah tanggungan keluarga dapat didominasikan dari 1 orang sampai 5 orang sebanyak 51 orang dengan persen 92,72\% (Tabel 2). Hal ini menunjukkan bahwa dalam jumlah tanggungan keluarga tersebut dapat dikatakan seimbang dengan in come (pendapatan) dari usaha peternak. Hal ini sesuai dengan pendapat Daniel (2002), yang menyatakan bahwa semakin besarnya jumlah anggota keluarga akan mempengaruhi keputusan petani dalam berusahatani. Semakin besarnya jumlah anggota petani atau peternak akan semakin besar pula tuntutan kebutuhan keuangan rumah tangga.

Tingkat generasi peternak dapat di dominasikan 1 generasi sampai 5 generasi dengan jumlah 53 orang dengan jumlah persen 96,36\% (Tabel 2). Berdasarkan tabel tersebut dapat dikatakan bahwa tingkat generasi peternak dapat dikatakan cukup baik. Semakin tinggi tingkat generasi peternak (pengalaman) beternak sudah semakin meningkat ilmu untuk mengembangkan usaha ternaknya.

\section{Rekapitulasi Hasil Analisis Pendapatan}

Data hasil analisis pendapatan ditampilkan pada Tabel 3. Usaha ternak kerbau di daerah penelitian diperoleh total pemasukan selama 1 (satu) tahun berkisar antar Rp 4.029.700.000 yang didominasi pada penjualan ternak sebanyak 99,009\% per tahun.

Total biaya pengeluaran pada usaha ternak kerbau meliputi: biaya bibit, biaya obatobatan, biaya kandang dan biaya pakan. Menurut data yang diperoleh selama 1 tahun dari usaha ternak kerbau adalah berkisar antara Rp 3.045.450.000/tahun yang didominasi pada biaya pengeluaran bibit ternak sebanyak $84,81 \%$ per tahun. 
Tabel 3. Rekapitulasi hasil analisis pendapatan

\begin{tabular}{|c|c|c|c|}
\hline Karakteristik peternak sampel & Total & Rataan/peternak & $\%$ \\
\hline $\begin{array}{l}\text { I. Pemasukan } \\
\text { - } \quad \text { Penjualan } \\
\quad \text { (Rp/ Tahun) } \\
\text { - } \quad \text { Penjualan Feses (Rp/tahun) }\end{array}$ & $\begin{array}{r}3.980 .000 .000 \\
59.700 .000\end{array}$ & $\begin{array}{l}72.363 .636 \\
1.085 .454\end{array}$ & $\begin{array}{l}99,009 \% \\
1,48 \%\end{array}$ \\
\hline Total pemasukan (Rp/tahun) & 4.029 .700 .000 & 73.087 .272 & $100 \%$ \\
\hline $\begin{array}{l}\text { II. Pengeluaran } \\
\begin{aligned} \text { - } & \text { Bibit (Rp/tahun) } \\
\text { - } & \text { Obat-obatan (Rp/tahun) } \\
\text { - } & \text { Kandang (Rp/tahun) } \\
\text { - } & \text { Pakan (Rp/tahun) }\end{aligned}\end{array}$ & $\begin{array}{r}1.990 .000 .000 \\
79.600 .000 \\
199.000 .000 \\
776.850 .000\end{array}$ & $\begin{array}{r}36.181 .818 \\
1.447 .272 \\
3.618 .181 \\
1.412 .454\end{array}$ & $\begin{array}{r}84,81 \% \\
3,39 \% \\
8,48 \% \\
3,31 \%\end{array}$ \\
\hline Total pengeluaran & 3.045 .450 .000 & 42.659 .725 & $100 \%$ \\
\hline $\begin{array}{l}\text { III. Komponen Analisis } \\
\quad \text { Pendapatan } \\
\text { Pemasukan ( Rp/thn) } \\
\text { Pengeluaran (Rp/thn) } \\
\text { Pendapatan bersih (Rp/thn) }\end{array}$ & $\begin{array}{c}4.029 .700 .000 \\
3.045 .450 .000 \\
984.250 .000\end{array}$ & $\begin{array}{l}73.087 .272 \\
42.659 .725 \\
30.427 .547\end{array}$ & \\
\hline
\end{tabular}

Sumber : Data Primer Penelitian (2014)

Pendapatan bersih setiap responden dari usaha ternak kerbau selama 1 tahun berkisar antara Rp 984.250.000 dengan rataan 30.427.547/peternak. Nilai pendapatan keluarga diperoleh dari usaha ternak kerbau. Digambarkan bahwa responden sudah termotivasi untuk mengembangkan usaha ternak kerbaunya. Tetapi mereka belum dapat menganalisis dengan baik bahwa usaha ternak kerbau yang mereka usahakan dapat mendatangkan pendapatan yang lebih besar apabila dilakukan dengan baik. Hal ini sesuai dengan pendapat Soekartawi (1984), yang menyatakan bahwa untuk mengembangkan usaha ternak, peternak harus mampu menganalisis dengan baik setiap usahanya untuk meningkatkan pendapatan yang lebih baik.

\section{Pengaruh Profil Peternak Kerbau}

Pengujian faktor-faktor yang mempengaruhi pendapatan peternak kerbau di kecamatan Lintong Nihuta, kabupaten Humbang Hasundutan digunakan analisi regresi linier berganda, yang menjadi variabel bebas (independent) adalah skala usaha $\left(\mathrm{X}_{1}\right)$ umur peternak $\left(\mathrm{X}_{2}\right)$, lama pendidikan $\left(\mathrm{X}_{3}\right)$, pengalaman beternak $\left(\mathrm{X}_{4}\right)$, jumlah tanggungan keluarga $\left(\mathrm{X}_{5}\right)$, tingkat generasi peternak $\left(\mathrm{X}_{6}\right)$, sedangkan yang menjadi variabel terikat tidak bebas (endependent) adalah pendapatan $(\mathrm{Y})$. 
Adapun hasil pengujian faktor-faktor yang mempengaruhi pendapatan peternak kerbau di Kecamatan Lintong Nihuta, Kabupaten Humbang Hasundutan dapat dilihat pada. Tabel analisis varian pendapatan dan hasil penduga parameter ditampilkan pada tabel berikut:

Tabel 4. Analisis varian pendapatan dan hasil penduga parameter

\begin{tabular}{lllll}
\hline Sumber & Derajat Bebas & F hitung & F table & $\begin{array}{l}\text { Tingkat } \\
\text { Signifikan }\end{array}$ \\
\hline $\begin{array}{l}\text { Regresi } \\
\text { Residual }\end{array}$ & 6 & 8,98 & 2209,62 & 0,000 \\
\hline Total & 48 & & & \\
\hline
\end{tabular}

Keterangan : F hitung : Skala Usaha, Umur peternak, Lama pendidikan, Pengalaman Peternak, Jumlah tanggungan keluarga, Tingkat Generasi berpengaruh nyata (pengaruh positif) terhadap pendapatan peternak dengan tarif signifikan 0.000 .

Tabel 5. Analisis regresi linier berganda pengaruh jumlah ternak (sakala usaha), umur peternak, lama pendidikan, pengalaman peternak, jumlah tanggungan keluarga dan tingkat generasi peternak

\begin{tabular}{lcrrr}
\hline Variabel & \multicolumn{1}{l}{ Koefisien } & \multicolumn{1}{l}{ Std. Error } & t-hitung & Signifikan \\
& Regresi & & & \\
\hline Konstanta & $3.118 .442,867$ & $1.034 .735,510$ & 3,014 & 0,004 \\
$\mathrm{X}_{1}$ & $2.116 .951,795$ & $41.686,731$ & 50,782 & 0,000 \\
$\mathrm{X}_{2}$ & $-32.516,300$ & $15.664,594$ & $-2,076$ & 0,043 \\
$\mathrm{X}_{3}$ & $125.813,117$ & $49.833,005$ & 2,525 & 0,015 \\
$\mathrm{X}_{4}$ & $5.416,425$ & $33.838,026$ & 0,160 & 0,873 \\
$\mathrm{X}_{5}$ & $-89.392,524$ & $53.712,025$ & $-1,664$ & 0,103 \\
$\mathrm{X}_{6}$ & $74.054,901$ & $70.989,992$ & 1,043 & 0,302 \\
R square & 0,996 & & & \\
Regresion & 0,998 & & & \\
Residual & 1,42 & & & \\
F-tabel & 2,31 & & & \\
$(\alpha=0,05)$ & & & & \\
T-tabel & 2,021 & & & \\
$(\alpha=0,05)$ & & & & \\
\hline Keterangan: & & & & \\
\end{tabular}

Keterangan:

$\hat{\mathrm{Y}} \quad$ : Pendapatan peternak kerbau

$\mathrm{X}_{1} \quad$ : Skala usaha (jumlah ternak kerbau) dalam Satuan Ternak (ST)

$\mathrm{X}_{2} \quad$ : Umur peternak (tahun)

$\mathrm{X}_{3} \quad$ : Lama pendidikan (tahun)

$\mathrm{X}_{4} \quad$ : Pengalaman peternak (tahun)

$\mathrm{X}_{5}$ : Jumlah tanggungan keluarga (orang)

$\mathrm{X}_{6} \quad$ : Tingkat generasi peternak (generasi)

Berdasarkan Tabel di atas di peroleh persamaan sebagai berikut:

$\hat{Y}=3.118 .442,867+2.116 .951,795 X_{1}-32.516,300 X_{2}+125.813,117 X_{3}+5.416,425 X_{4}-$ $89.392,524 \mathrm{X}_{5}+74.054,901 \mathrm{X}_{6}+\mu$ 
Berdasarkan hasil regresi di atas dapat diketahui:

1. Nilai konstanta atau intersept adalah sebesar 3.118.442,867. Artinya apabila variabel bebas yaitu skala usaha (jumlah ternak), umur peternak, lama pendidikan, pengalaman peternak, jumlah tanggungan keluarga dan tingkat generasi tidak ada maka peternak kerbau tetap memperoleh pendapatan sebesar nilai konstanta yaitu 3.118.442,867.

2. R Square 0,996 bernilai artinya bahwa semua variabel bebas skala usaha ternak (jumlah ternak), umur peternak, lama pendidikan, pengalaman peternak, jumlah tanggungan keluarga dan tingkat generasi mempengaruhi variabel terikat sebesar 99,6 \% dan selebihnya yaitu sebesar $0,5 \%$ dijelaskan oleh variabel lain $(\mu)$ yang tidak diteliti dalam penelitian ini.

3. Secara serempak nilai F-hitung $(8,98)$ lebih besar dari pada F-tabel $(2,31)$. Hal ini menunjukkan bahwa secara serempak ke enam variabel tersebut yaitu skala usaha, umur peternak, lama pendidikan, pengalaman peternak, jumlah tanggungan keluarga dan tingkat generasi berpengaruh secara nyata (ada pengaruh positif) terhadap pendapatan peternak kerbau dengan tarif signifikan 0.000 dan pada taraf kepercayaan $95 \%$.

4. Secara parsial nilai T-hitung variabel yang mempengaruhi adalah variabel jumlah ternak (skala usaha) 50,782, variabel umur peternak (-2,076), variabel lama pendidikan $(2,525)$, variabel pengalaman peternak $(0,160)$ variabel jumlah tanggungan keluarga (1,664) dan variabel tingkat generasi peternak $(1,043)$.

a. Variabel jumlah ternak kerbau berpengaruh nyata terhadap pendapatan peternak kerbau, jika diukur pada tingkat kepercayaan 95\% yang ditunjukkan oleh nilai thitung $\left(\mathrm{X}_{1}\right)$ sebesar 50,782 lebih besar dari t-tabel $(\alpha=0.05)$ yakni sebesar 2,021. Hal ini menunjukkan bahwa semakin banyak ternak yang dipelihara maka akan semakin besar pula pendapatan yang akan diperoleh peternak kerbau. Menurut Soekartawi (1995), bahwa pendapatan usaha ternak kerbau sangat dipengaruhi oleh banyaknya ternak yang dijual oleh peternak itu sendiri sehingga semakin banyak jumlah ternak kerbau maka semakin tinggi pendapatan bersih yang diperoleh.

b. Variabel umur peternak berpengaruh nyata terhadap pendapatan ternak kerbau, jika diukur pada tingkat kepercayaan 95\% yang ditunjukkan oleh nilai thitung $\left(\mathrm{X}_{2}\right)$ sebesar 0,43 lebih $>$ dari T-tabel $(\alpha=0,05)$ yakni sebesar 2,021 variabel ini bernilai negatif karena disebabkan kriteria umur peternak tidak 
mendorong peternak dalam mengembangkan usaha ternak kerbau di kecamatan Lintong Nihuta. Faktor umur biasanya lebih diidentikkan dengan produktifitas kerja jika seseorang masih tergolong usaha produktif ada kecenderungan produktifitasnya juga tinggi Chamdi (2003), mengemukakan bahwa semakin mudah usia peternak (usia produktif 16-60 tahun) umumnya rasa keingintahuan terhadap sesuatu semakin tinggi dan minat untuk mengadopsi terhadap introduksi teknologi semakin tinggi.

c. Variabel pendidikan berpengaruh nyata terhadap pendapatan peternak kerbau, jika diukur pada tingkat kepercayaan 95\% yang ditunjukkan t-hitung $\left(\mathrm{X}_{3}\right)$ sebesar 0,015 lebih > dari nilai t-tabel $(\alpha=0.05)$ yakni sebesar 2,021. Hal ini menunjukkan bahwa pendidikan tidak dapat memberikan dorongan terhadap pendapatan peternak. (Soekartawi, 1984) menyatakan bahwa pendidikan peternak cenderung mempengaruhi cara berpikir dan tingkat penerimaan mereka terhadap inovasi dan teknologi baru.

d. Variabel pengalaman peternak tidak berpengaruh nyata terhadap pendapatan peternak kerbau, jika diukur dari pada tingkat kepercayaan 95\% yang ditunjukkan t-hitung $\left(\mathrm{X}_{4}\right)$ sebesar 0,873 lebih $>$ dari nilai t-tabel $(\alpha=0.05)$ yakni sebesar 2,021. Hal ini menunjukkan bahwa pengalaman beternak 1-24 tahun. Umumnya pengalaman beternak diperoleh dari orang tuanya secara turuntemurun. Dengan pengalaman beternak yang cukup lama memberikan indikasi bahwa pengetahuan dan keterampilan peternak terhadap manajemen pemeliharaan ternak mempunyai kemampuan yang lebih baik. Namun di lapangan tidak diperoleh pengaruh seperti yang diharapkan. Hal ini dapat disebabkan banyak peternak yang memiliki pengalaman yang memadai namun masih mengelola usaha tersebut dengan kebiasaan-kebiasaan lama yang sama dengan sewaktu mereka mengawali usahanya sampai sekarang.

e. Variabel jumlah tanggungan keluarga tidak berpengaruh nyata terhadap pendapatan peternak kerbau, jika diukur pada tingkat kepercayaan 95\% yang ditunjukkan oleht-hitung $\left(\mathrm{X}_{5}\right)$ sebesar 0,103 lebih $<$ dari t-tabel $(\alpha=0.05)$ yakni sebesar 2,021. Hal ini menunjukkan bahwa tanggungan anak dalam keluarga peternak tidak dapat memberikan dorongan positif terhadap peningkatan pendapatan peternak.

f. Variabel tingkat generasi peternak tidak berpengaruh nyata terhadap pendapatan peternak kerbau, jika diukur tingkat kepercayaan 95\% yang ditunjukkan oleh t- 
hitung $\left(\mathrm{X}_{6}\right)$ sebesar 0,302 lebih $<$ dari t-tabel $(\alpha=0.05)$ yakni sebesar 2,021. Hal ini menunjukkan tingkat generasi peternak tidak dapat memberikan dorongan positif terhadap peningkatan pendapatan peternak.

5. Arti dari nilai persamaan berikut adalah:

$$
\begin{aligned}
& \hat{Y}=3.118 .442,867+2.116 .951,795 X_{1} 32.516,300 X_{2}+125.813,117 X_{3}+ \\
& 5.416,425 X_{4}-89.392,524 X_{5}+74.054,901 X_{6}+\mu
\end{aligned}
$$

Berdasarkan model persamaan di atas dapat diinterpresikan bahwa:

a. Apabila variabel bebas jumlah ternak $\left(X_{1}\right)$ mengalami kenaikan sebesar $1 \mathrm{ST}$, maka akan terjadi kenaikan pendapatan (Y) sebesar Rp 2.116.951,795.

b. Apabila variabel bebas umur peternak mengalami penurunan sebesar 1 tahun, maka akan terjadi penurunan pendapatan (Y) sebesar $\quad$ Rp 32.516,300.

c. Apabila variabel bebas lama pendidikan mengalami kenaikan sebesar 1 tahun, maka akan terjadi kenaikan pendapatan peternak (Y) sebesar Rp $125.813,117$.

d. Apabila variabel bebas pengalaman peternak mengalami peningkatan sebesar 1 tahun, maka akan terjadi peningkatan peternak (Y) sebesar Rp 5.416,425.

e. Apabila variabel bebas jumlah tanggungan keluarga mengalami kenaikan sebesar 1 tahun, maka akan terjadi kenaikan peternak (Y) sebesar $\mathrm{Rp}$ $89.392,524$

f. Apabila variabel bebas tingkat generasi peternak mengalami kenaikan sebesar 1 generasi, maka akan terjadi kenaikan pendapatan peternak (Y) sebesar Rp 74.054,901.

g. Apabila varibel $\mathrm{X}_{1}, \mathrm{X}_{2}, \mathrm{X}_{3}, \mathrm{X}_{4}, \mathrm{X}_{5}$ dan $\mathrm{X}_{6}$ yang di analisis di anggap nol (tidak melakukan aktivitas), maka peternak kerbau akan menanggung biaya sebesar Rp 3.118.442,867/tahun atau Rp 259.870,238/bulan.

Karakteristik sosial peternakan di Kecamatan Lintong Nihuta Kabupaten Humbang Hasundutan mempunyai beberapa variabel yang berpengaruh nyata dan tidak nyata. Karakteristik tersebut dapat dilihat pada Tabel 6.

Variabel skala usaha, umur peternak, lama pendidikan peternak berpengaruh nyata terhadap pendapatan peternak.Sedangkan variabel pengalaman peternak, jumlah tanggungan keluarga dan tingkat generasi peternak memberikan pengaruh yang tidak nyata terhadap pendapatan peternak kerbau di Kecamatan Lintong Nihuta Kabupaten Humbang Hasundutan. 
Tabel 6. Rekapitulasi data

\begin{tabular}{lll}
\hline Karakteristik sosial peternak & Signifikan & Keterangan \\
\hline Skala usaha & 0,000 & Berpengaruh nyata \\
Umur peternak & 0,043 & Berpengaruh nyata \\
Lama pendidikan & 0,015 & Berpengaruh nyata \\
Pengalaman beternak & 0,873 & Berpengaruh tidak nyata \\
Jumlah tanggungan keluarga & 0,103 & Berpengaruh tidak nyata \\
Tingkat generasi peternak & 0,302 & Berpengaruh tidak nyata \\
\hline
\end{tabular}

\section{KESIMPULAN}

Berdasarkan hasil penelitian analisis profil peternak terhadap pendapatan peternak kerbau di Kecamatan Lintong Nihuta Kabupaten Humbang Hasundutan dapat disimpulkan yaitu: pendapatan usaha ternak kerbau di Kecamatan Lintong Nihuta dipengaruhi oleh faktor skala usaha, umur peternak, lama pendidikan peternak yang berpengaruh positif dalam meningkatkan pendapatan peternak kerbau. Pengalaman peternak, jumlah tanggungan keluarga dan tingkat generasi peternak memberikan pengaruh yang tidak nyata terhadap pendapatan peternak kerbau di Kecamatan Lintong Nihuta Kabupaten Humbang Hasundutan.

\section{DAFTAR PUSTAKA}

Ahmadi, A. H., 2003. Sosiologi Pendidikan. Penerbit PT. Rineka Cipta. Jakarta.

Badan Pusat Statistik, 2011. Kabupaten Humbang Hasundutan, BPS Sumatera Utara, Medan.

Chamdi, A.N, 2003. Kajian Profil Sosial Ekonomi Usaha Babi di Kecamatan Kradenan Kabupaten Grobongan, Prosiding Seminar Nasional Teknologi Peternakan dan Veteriner, Bogor 29-30 September 2003, Bogor: Puslitbang Peternakan Departemen Pertanian.

Daniel, M, 2002. Pengantar Ekonomi Pertanian. Bumi Aksara, Jakarta.

Hasan, I., 2000. Analisis Produksi Kopi di Desa Mbenti Kecamatan Minyambow Kabupaten Manokwari.

Pryanto, 2000. Potensi Kambing Peranakan Etawah ( PE) dan Upaya Pola Konservesi di Daerah Sumber Bibit. Pros. Seminar Nasional Peternakan dan Veteriner, Bogor.

Soekartawi, A., Soeharjo, Dillon, J.L.,Hardaker,J.B., 1984. Ilmu Usaha Tani dan Penelitian Untuk Perkembangan Peternak Kecil, UI Press, Jakarta.

Soekartawi, 1995. Analisis Usahatani. Universitas Indonesia. Jakarta.

Sudjana, 2002. Metode Statistika. Tarsito. Bandung. 
Suryana A, 2000. Harapan dan Tantangan Bagi Subsektor Peternakan Dalam Meningkatkan Ketahanan Pengan Nasional. Pros. Seminar Nasional Peternakan Dan Veteriner, Bogor.

Wirartha, I. M. 2006. Meteologi Penelitian Sosial Ekonomi. Penerbit Audi. Yogyakarta. 